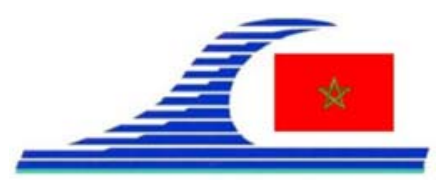

Conférence Méditerranéenne Côtière et Maritime EDITION 2, TANGER, MAROC (2011)

Coastal and Maritime Mediterranean Conference

Disponible en ligne - http://www.paralia.fr-Available online

\title{
Technical feasibility of using thermogravimetry for monitoring contamination of marine and lake sediments
}

\author{
Rocío RODRIGUEZ-BARROSO ${ }^{\mathbf{1}}$, Youssef BENHAMOU ${ }^{\boldsymbol{1}}$, \\ Bouchta EL MOUMNI ${ }^{2}$, José Luis GARCIA-MORALES ${ }^{1}$
}

1. Dept of Environmental Technologies, University of Cadiz, 11510. Puerto Real, Spain. rocio.rodriguez@uca.es

2. Dept of Earth Sciences and Oceanology, University of Abdelmalek Essaadi Tangier, 416, Tangier, Morocco.

\begin{abstract}
:
This work assesses the contamination of sediments from two rivers and the Bay of Tangier in northern Morocco, by applying a protocol based on thermal analysis applied to sediments in southern Spain and recently published (RODRÍGUEZ-BARROSO et al., 2010).
\end{abstract}

Keywords:

Thermal analysis - Sediment - Contamination - Tangier Bay - Morocco - Metal pollution index

\section{Introduction}

Thermogravimetry (TG) was used to investigate the pollution on marine and river sediments close to urban and industrial sites in northern Morocco. Sediment weight loss when heated (TG) was performed under oxidizing conditions from $250^{\circ} \mathrm{C}$ to $900^{\circ} \mathrm{C}$. The first derivative of TG curves was used to generate a Cartesian diagram for sediment cataloging, in a quick way, according to their organic matter and grain size contents. In this diagram, sediments placed to the right side, characterized by a prevalence of the fine fraction and high organic matter content, are mainly sediments from Mghogha river, while samples with a large sandy fraction placed to the left side of the diagram are characterized by large sandy fractions, and in general, low organic matter contents, sediments from Tangier Bay and Souani river.

\section{Materials and methods}

16 stations from two rivers (Souani and Mghogha) in the north of Morroco (Tangier) and 11 stations from the bay of Tangier were studied. All are characterized by receiving effluents from the adjacent populations. Some of the cities in these zones have not treated their effluents until recent years, therefore the sediments close to the discharge channels have been subjected to substantial contamination of urban origin. 
La connaissance de la Mer :

un vecteur du développement durable en Méditerranée

\subsection{Thermal analyses}

Thermal analyses (TGA) were carried out using Perkin- Elmer TGA7 modular equipment with a microbalance ( $0.1 \mathrm{~g}$ sensitivity) and a furnace element with a chromel-alumel thermocouple. Prior analyzer calibration was performed from the onset temperature corresponding to Curie Points of nickel and perkalloy. For weight calibration a $100 \mathrm{mg}$ ClassM reference was used. In several previous works we have demonstrated the utility of the thermoanalysis technique for the evaluation of organic matter and heavy metals in ground sediment (RODRÍGUEZ-BARROSO et al., 2006, 2008). In order to optimize these determinations, we concluded that bulk sediments, recently collected, should first be washed according to the following protocol: (1). Centrifugation of $3 \mathrm{~g}$ of bulk sediment for $3 \mathrm{~min}$ at $2000 \mathrm{rpm}$. (2). Removal of the supernatant layer. (3). Addition of $8 \mathrm{ml}$ of water (Milli-Q quality). (4). $2 \mathrm{~min}$ "vortex" and 15 min shaken. (5). Centrifugation for $3 \mathrm{~min}$ at $2000 \mathrm{rpm}$. (6). Removal of the supernatant layer. (7). Drying for $1 \mathrm{~h}$ at $105^{\circ} \mathrm{C}$. (8). Grinding manually in an agate mortar. (9). TGA analysis.

An aliquot of sediment $(30 \mathrm{mg})$ was heated at $100^{\circ} \mathrm{C}$ for $30 \mathrm{~min}$ and then until $900^{\circ} \mathrm{C}$ with a constant heating rate $\left(5^{\circ} \mathrm{C} \mathrm{min}^{-1}\right)$ in an oxygen atmosphere. This analytical procedure has the advantage of providing results in $4-5 \mathrm{~h}$, and according to LÓPEZCAPEL et al. (2006), requires only a small amount of dry sediment (30 mg), and allows very useful correlations to be obtained between organic matter and thermal parameters, for estimating the level of contamination in sediments (RODRÍGUEZ-BARROSO et al., 2006, 2008, 2009).

\section{Results}

The results of thermal analysis are presented in Table 1 as the relative weight losses ( $\triangle \mathrm{W} \%$ of total sample weight) that occur when heating the samples at the 2 temperature ranges $250-650^{\circ} \mathrm{C}\left(\mathrm{W}_{1}\right)$ and $650-900^{\circ} \mathrm{C}\left(\mathrm{W}_{2}\right)$. The total weight loss $\left(\mathrm{W}_{\text {total }}\right.$; sum $\mathrm{W}_{1}$ and $\mathrm{W}_{2}$ ) and the percentage in each range of temperature relative to Wtotal are also shown. In a previous study (RODRÍGUEZ-BARROSO et al., 2006), we have reported that weight loss in the $250-400^{\circ} \mathrm{C}$ range could be considered as an estimation of the organic matter content of the sediment and those above $600^{\circ} \mathrm{C}$ as an estimation of the granulometric and mineralogic characteristics of the sediment. Additionally, we have proved (RODRÍGUEZ-BARROSO et al., 2008, 2009) that other pollutant elements, like heavy metals $(\mathrm{Ni}, \mathrm{Cu}, \mathrm{Cr}, \mathrm{Cd}$, and $\mathrm{Zn}$ ) and nutrient such as total nitrogen, could be absorbed and/or form organometallic complexes with the organic matter incorporated into the sediments. A better understanding of the sediment characteristics from thermogravimetric curves can be acquired when carrying out a Cartesian diagram with direct regard to sediment composition (RODRÍGUEZ-BARROSO et al., 2010). The diagram represents $\mathrm{W}_{1}$ versus $\mathrm{W}_{2}$ and the meaning of both axes could be related with the organic pollution level (organic matter content, nutrients, and heavy metals) 
represented in the abscissa axis $\left(\mathrm{W}_{1}\right)$, while the grain size and mineralogical composition are mainly represented in the ordinate axis $\left(\mathrm{W}_{2}\right)$. Consequently, each point in the diagram is assigned to each sample according to its weight loss in both ranges of temperatures.

The Cartesian diagram obtained in this way, with the position for each sample, is shown in figure 1 (Souani and Mghogha rivers) and figure 2 (Tangier Bay). Table 1 has been taken into account for the interpretation of the graphic. Samples located in the left side are characterized by a high percentage of sandy fractions in their granulometric composition and, in general, low organic matter content. In contrast, samples located at the right show a prevalence of the clay and silt fractions and large organic carbon content. Then, two zones on the graph would differentiate; therefore samples placed to the right would have a higher probability of heavy metals contamination.

In fact, samples M2, M3 and M6 are silt-clay composition, M5 is sandy-silt-clay and M4 clayey-sand compositions and are located to the right of the diagram, and the organic carbon contained for this group of samples ranged between $0.7 \%$ (for M2) and $9.5 \%$ (for M6). It could be concluded with respect to the abscissa axis $\left(\mathrm{W}_{1}\right)$, that the samples located further to the right contain the highest percentage of organic compounds. Also, S1 (silty-sand) and S6 (sandy-silt-clay) compositions are located to the right of the diagram with low organic carbon content $(1.5 \%$ and $2.1 \%$, respectively).

The other samples are sandy textured (M7, M8, S2, S4, S5, S7, S8, B5, B6, B7 and B8) or silty sand (M1, S3, B3, B4, B9, B11) or sand-silt-clay (S3, B1) or silty-clay (B2, $\mathrm{B} 10)$ and are located in the left of the diagram; these sediments showed lower organic carbon content, between $0.1 \%$ and $1.5 \%$ for Bay samples, between 0.2 and $0.5 \%$ for Mghogha samples and between 0.4 and $1.9 \%$ for Souani samples. In relation to the ordinate axis $\left(\mathrm{W}_{2}\right)$, it could be concluded that the samples located at the top of the diagram are characterized by a high content of coarse fractions and those placed in the bottom contain a higher percentages of fine ones.

For validation of the Cartesian diagram based on the overall metal contents at the sites investigated, metal pollution index (MPI) could be used. This index has been used by different authors and applied in marine sediments and is calculated according to USERO et al. (2000) with the formula:

MPI $=\left(\mathrm{C} f_{1} \times \mathrm{C} f_{\mathrm{s}} \mathrm{x} \ldots \mathrm{x} \mathrm{C} f_{\mathrm{n}}\right)^{1 / n}$;

where $\mathrm{C} f_{\mathrm{n}}$ is the concentration of the metal $n$ in the samples. Generally, high MPI values are indicative of important metal content in the sediment and therefore high organic compound could be predicted. For this reason, it was expected that samples located to the right of the diagram present the highest MPI values; hence, this index could be useful to validate the reliability of the Cartesian diagram.

The MPI values of seven metals ( $\mathrm{Mn}, \mathrm{Cr}, \mathrm{Cu}, \mathrm{Ni}, \mathrm{Pb}, \mathrm{Zn}$ and $\mathrm{Cd}$ ) obtained in previous works for sediments of the area under investigation, are summarized in table 1 . The 
La connaissance de la Mer :

un vecteur du développement durable en Méditerranée

lowest MPI values were recorded at stations characterized with coarse fractions (S7, S8, M7, M8, S5, B5, B7 and B8) (overall MPI = 8.7) in agreement with the sandy sediments. They are located on the left of the Cartesian diagram. While the rest of stations showed higher MPI, fine granulometric composition prevailed and were located at the right of the diagram. It could be concluded that the highest values of MPI are in agreement with the fine sediment composition with a great capacity for adsorbing organic matter that could form the organometallic complexes and retain higher metal content.

Table 1. Weight losses (\% of total sample weight) corresponding to the both temperature ranges $\left({ }^{\circ} \mathrm{C}\right)$, and total weight $(\%)$; the percentages relative to $W_{\text {total }}$ are also shown. Metal pollution index (MPI) and organic carbon (OC).

\begin{tabular}{|c|c|c|c|c|c|c|c|c|}
\hline \multirow[t]{2}{*}{ Zones } & \multirow{2}{*}{$\begin{array}{c}\text { Stations } \\
B 1\end{array}$} & \multicolumn{2}{|c|}{$\begin{array}{c}W_{1}(\%) \\
\left(250-600{ }^{\circ} \mathrm{C}\right)\end{array}$} & \multicolumn{2}{|c|}{$\begin{array}{c}W_{2}(\%) \\
\left(600-900{ }^{\circ} \mathrm{C}\right)\end{array}$} & \multirow{2}{*}{$\begin{array}{c}\begin{array}{c}W_{\text {total }}(\%) \\
\left(250-900^{\circ} \mathrm{C}\right)\end{array} \\
11.66\end{array}$} & \multirow{2}{*}{$\begin{array}{c}\text { MPI } \\
32\end{array}$} & \multirow{2}{*}{$\frac{\text { OC (\%) }}{0.9}$} \\
\hline & & 4.21 & $(36.1)^{a}$ & 7.45 & $(63.9)^{a}$ & & & \\
\hline \multirow{10}{*}{ 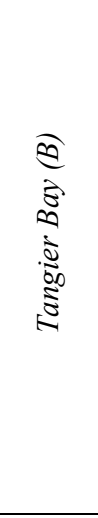 } & $B 2$ & 4.57 & $(48.9)^{a}$ & 4.78 & $(51.1)^{a}$ & 9.35 & 26 & 0.6 \\
\hline & B3 & 3.24 & $(27.4)^{a}$ & 8.57 & $(72.6)^{a}$ & 11.81 & 34 & 1.4 \\
\hline & $B 4$ & 2.85 & $(21.6)^{a}$ & 10.36 & $(78.4)^{a}$ & 13.21 & 23 & 0.6 \\
\hline & B5 & 0.66 & $(11.6)^{a}$ & 5.04 & $(88.4)^{a}$ & 5.7 & 9 & 0.1 \\
\hline & B6 & 2.43 & $(9.9)^{a}$ & 22.04 & $(90.1)^{a}$ & 24.47 & 29 & 0.7 \\
\hline & $B 7$ & 1.01 & $(7.0)^{a}$ & 13.5 & $(93.0)^{a}$ & 14.51 & 8 & 0.3 \\
\hline & $B 8$ & 1.57 & $(13.0)^{a}$ & 10.51 & $(87.0)^{a}$ & 12.08 & 8 & 0.2 \\
\hline & B9 & 3.81 & $(23.3)^{a}$ & 12.55 & $(76.7)^{a}$ & 16.36 & 26 & 1.1 \\
\hline & $B 10$ & 2.56 & $(50.3)^{a}$ & 2.53 & $(49.7)^{a}$ & 5.09 & 35 & 1.6 \\
\hline & $B 11$ & 3.09 & $(30.5)^{a}$ & 7.04 & $(69.5)^{a}$ & 10.13 & 30 & 0.8 \\
\hline \multirow{8}{*}{ 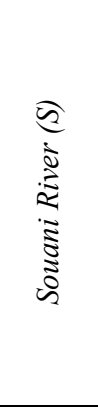 } & S1 & 5.84 & $(41.79)^{a}$ & 8.17 & $(58.3)^{a}$ & 14.01 & 38 & 1.5 \\
\hline & $S 2$ & 2.4 & $(9.3)^{a}$ & 23.46 & $(90.7)^{a}$ & 25.86 & 24 & 0.4 \\
\hline & $S 3$ & 4.06 & $(26.7)^{a}$ & 11.13 & $(73.3)^{a}$ & 15.19 & 17 & 0.6 \\
\hline & $S 4$ & 5.03 & $(22.2)^{a}$ & 17.62 & $(77.8)^{a}$ & 22.65 & 35 & 3.9 \\
\hline & S5 & 3.52 & $(17.0)^{a}$ & 17.19 & $(83.0)^{a}$ & 20.71 & 36 & 1.9 \\
\hline & S6 & 5.17 & $(36.6)^{a}$ & 8.94 & $(63.4)^{a}$ & 14.11 & 41 & 2.1 \\
\hline & $S 7$ & 1.15 & $(6.9)^{a}$ & 15.54 & $(93.1)^{a}$ & 16.69 & 10 & 0.2 \\
\hline & S8 & 1.45 & $(7.9)^{a}$ & 16.97 & $(92.1)^{a}$ & 18.42 & 10 & 0.2 \\
\hline \multirow{8}{*}{ 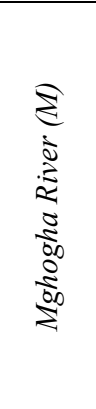 } & $M 1$ & 3.62 & $(36.6)^{a}$ & 6.26 & $(63.4)^{a}$ & 9.88 & 48 & 0.5 \\
\hline & $M 2$ & 5.03 & $(65.8)^{a}$ & 2.61 & $(34.2)^{a}$ & 7.64 & 38 & 0.7 \\
\hline & $M 3$ & 5.41 & $(60.0)^{a}$ & 3.6 & $(40.0)^{a}$ & 9.01 & 66 & 1.9 \\
\hline & M4 & 8.48 & $(42.5)^{a}$ & 11.48 & $(57.5)^{a}$ & 19.96 & 52 & 5.5 \\
\hline & M5 & 9.84 & $(46.2)^{a}$ & 11.46 & $(53.8)^{a}$ & 21.3 & 56 & 9.8 \\
\hline & M6 & 11.58 & $(58.1)^{a}$ & 8.35 & $(41.9)^{a}$ & 19.93 & 42 & 9.5 \\
\hline & $M 7$ & 1.37 & $(8.0)^{a}$ & 15.86 & $(92.0)^{a}$ & 17.23 & 8 & 0.3 \\
\hline & M8 & 1.25 & $(6.6)^{a}$ & 17.56 & $(93.4)^{a}$ & 18.81 & 8 & 0.2 \\
\hline
\end{tabular}

${ }^{a}$ Percentage relative to $W_{\text {total }}$ 


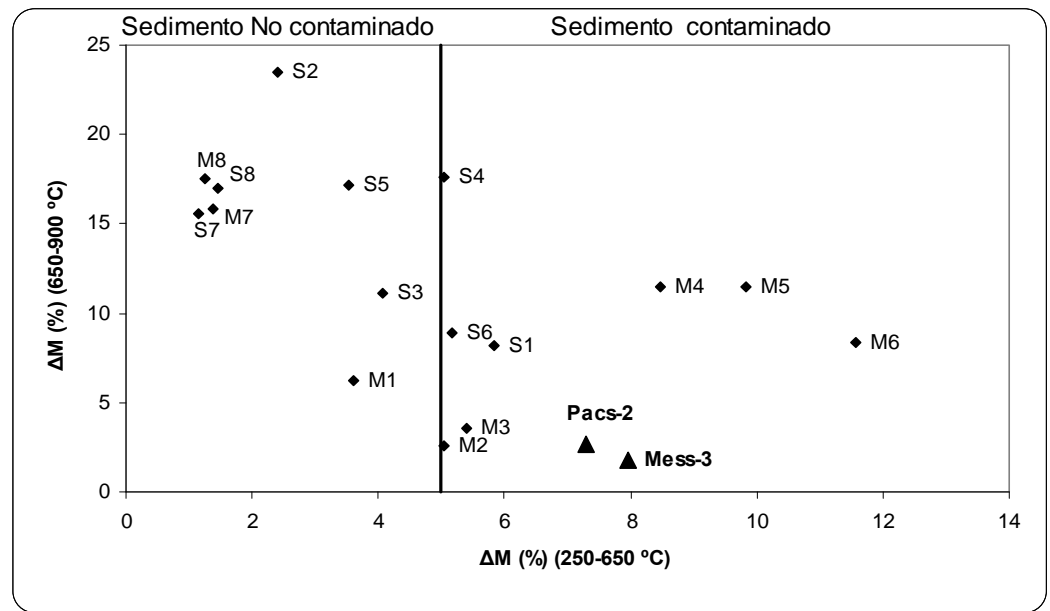

Fig. 1 Approach of polluted sediment by Cartesian diagram based on thermogravimetric data for river sediments (Souani, S and Mghogha, M)

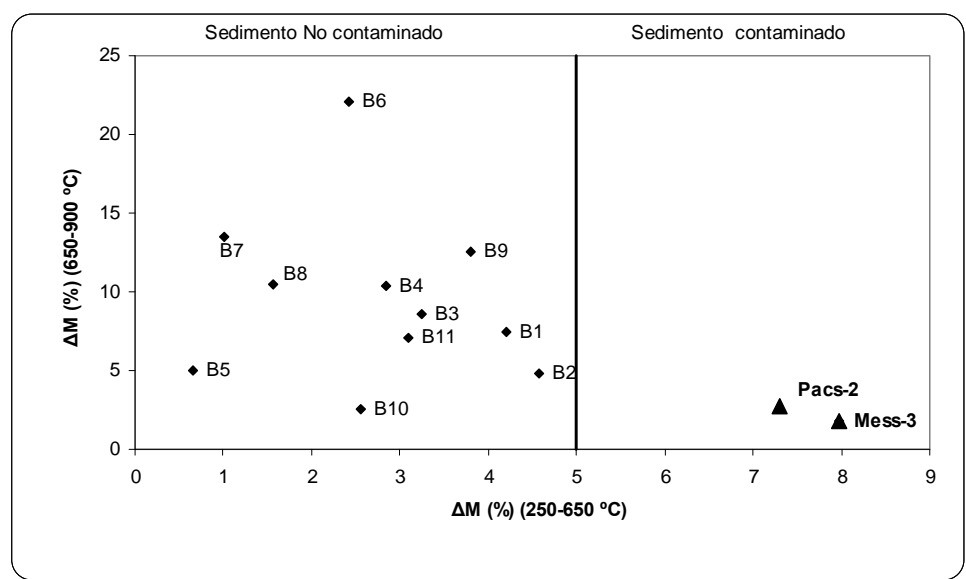

Fig. 2 Approach of polluted sediment by Cartesian diagram based on thermogravimetric data for bay Tangier sediments

\section{Conclusions}

RODRÍGUEZ-BARROSO et al. (2010) concluded the text. This study provides a tool for pre-selecting the most polluted sediments based in thermogravimetric analyses. The procedure consists in a pre-wash or pre-treatment of the sediments recently picked up and then, a thermogravimetric analysis. The weight losses at two temperature ranges $250-600^{\circ} \mathrm{C}\left(\mathrm{W}_{1}\right)$ and $600-900^{\circ} \mathrm{C}\left(\mathrm{W}_{2}\right)$ are evaluated and are represented in a Cartesian diagram. Sediments located at the right of the Cartesian diagram have a high probability of being very thin material with high organic and metal contents, and sediments left of the diagram have a high probability of being thickly particulate material with low metal and organic content. Thermal analysis proves to be a very simple and reproducible technique which can be applied to the whole sample, with a short pre-treatment. 
La connaissance de la Mer:

un vecteur du développement durable en Méditerranée

Therefore, this could be an optimum tool for monitoring a potential contamination and for pre-selecting sediments which require further characterization analyses.

This screening method evaluated Mghogha River at a higher pollution than the Souani or Bay, coinciding with the results of metal pollution index (MPI).

Finally, the authors want to clarify that this procedure is not proposed as a general replacement for the standard methods of analysis, but as an additional and complementary novel method, that could alert the authorities to possible changes in contamination.

\section{Acknowledgements}

This research was supported by the Spanish International Development Cooperation Agency (AECID) within the framework of the Programme of Interuniversity and Scientific Research Cooperation between Spain and Morocco, by several project, grant No. A/8192/07, A/017905/08, A/023497/09, A/032075/10, C/032804/10.

\section{References}

LÓPEZ-CAPEL E., ROSA J.R., GONZÁLEZ-VILA F.J., GONZÁLEZ-PÉREZ J.A., MANNING D.A.C. (2006). Elucidation of different forms of organic carbon in marine sediments from the Atlantic coast of Spain using thermal analysis coupled to isotope ratio and quadrupole mass spectrometry. Organic Geochemistry, 37, pp 1983-1994. doi:10.1016/j.orggeochem.2006.07.025

RODRÍGUEZ-BARROSO M.R., RAMÍREZ-DEL SOLAR M., BLANCO E., QUIROGA J.M., GARCÍA-MORALES J.L. (2006). Thermal analysis in the evaluation of sediment pollution. Environmental Technology, 27, pp 1001-1009. doi:10.1080/09593332708618708

RODRÍGUEZ-BARROSO M.R., RAMÍREZ-DEL SOLAR M., BLANCO E., QUIROGA J.M., GARCÍA-MORALES J.L. (2008). Qualitative estimation of heavy metals in marine sediment using thermal analysis. Soil and Sediment Contamination: an International Journal. 17, pp 107-120.

RODRÍGUEZ-BARROSO M.R., RAMÍREZ-DEL SOLAR M., BLANCO E., QUIROGA J.M., GARCÍA-MORALES J.L. (2009). Thermal gravimetry analysis assessed as an alternative method for characterization of sediment contamination. Environmental Engineering Science, 26, pp 279-287. doi:10.1089/ees.2007.0221

RODRÍGUEZ-BARROSO M.R., GARCÍA-MORALES J.L., RAMÍREZ-DEL SOLAR M., BLANCO E., QUIROGA J.M. (2010). Thermal analysis as a first screening method to evaluate potential contamination. Water, Air and Soil Pollution, 208, pp 173-182. doi:10.1007/s11270-009-0157-y

USERO J., GRACIA I., LEAL A., FRAIDÍAS J. (2000). Calidad de las aguas y sedimentos del Litoral Andaluz. Consejería de Medio Ambiente de la Junta de Andaluc. 